University of Nebraska - Lincoln

DigitalCommons@University of Nebraska - Lincoln

1975

\title{
The Effect of Microcrack Dilatancy on the Permeability of Westerly Granite
}

Mark D. Zoback

U.S. Geological Survey, zoback@stanford.edu

James D. Byerlee

Stanford University

Follow this and additional works at: https://digitalcommons.unl.edu/usgsstaffpub

Part of the Earth Sciences Commons

Zoback, Mark D. and Byerlee, James D., "The Effect of Microcrack Dilatancy on the Permeability of Westerly Granite" (1975). USGS Staff -- Published Research. 451.

https://digitalcommons.unl.edu/usgsstaffpub/451

This Article is brought to you for free and open access by the US Geological Survey at DigitalCommons@University of Nebraska - Lincoln. It has been accepted for inclusion in USGS Staff -- Published Research by an authorized administrator of DigitalCommons@University of Nebraska - Lincoln. 


\title{
The Effect of Microcrack Dilatancy on the Permeability of Westerly Granite
}

\author{
Mark D. Zoback and James D. Byerlee \\ U.S. Geological Survey, Menlo Park, Califormia 94025 \\ Department of Geophysics, Stanford University, Stanford, California 94305
}

\begin{abstract}
Permeability and volumetric strain were measured under constant confining pressure and pore pressure as a function of increasing and decreasing differential stress. Permeability was found to increase appreciably during dilatancy. Our results have also shown that permeability and dilatant volume changes are not unique functions of differential stress and that permeability changes with differential stress are not uniquely dependent upon dilatant volume changes. Most significant, however, is that if dilatancy-fluid diffusion occurs in situ, our results indicate that microcrack dilatancy is not a reasonable physical mechanism to account for such a phenomenon.
\end{abstract}

The report of Nersesov et al. [1969] and Semenov [1969] of travel time anomalies preceding earthquakes in the Garm region of central Asia led $\mathrm{Nur}$ [1972] to propose the now familiar dilatancy-fluid diffusion theory. Scholz et al. [1973] and others have subsequently related other earthquake phenomena to the dilatancy-fluid diffusion theory. Since the proper interpretation of field data requires an understanding of fluid flow in dilatant rock, laboratory experiments were undertaken to investigate this phenomenon.

In this study we consider the effect of microcrack dilatancy on the permeability of Westerly granite. Comparison of permeability changes to dilatant (or nonelastic) volume changes may enable us to extend our results to other materials that exhibit microcrack dilatancy and possibly to predict in situ permeability changes resulting from inferred dilatant volume changes.

The permeability of Westerly granite has previously been investigated by Brace et al. [1968]. The effects of hydrostatic confining pressure and pore pressure on permeability were considered in that study. Dilatancy in Westerly granite has also been discussed by Brace et al. [1966]. In that study, dilatant volume changes were observed in a variety of crystalline rocks under different confining pressures and at different loading rates. Dilatant volume changes associated with cyclically applied differential stress are discussed elsewhere [Zoback and Byerlee, 1974].

\section{Experimental Procedure}

In our investigation, permeability was measured as the samples were deformed under constant confining pressure and constant pore pressure. Volumetric strain was measured in the manner described by Brace et al. [1966], strain gauges were attached to the sample, and volumetric strain was computed by summing the axial strain with twice the circumferential strain.

Figure 1 is a schematic illustration of the pore pressure system, sample assembly, and triaxial apparatus used in the experiments. A cylindrical sample $(6.35 \mathrm{~cm}$ long and $2.54 \mathrm{~cm}$ in diameter) was enclosed in a thin copper jacket. Permeability and volumetric strain could then be measured as the confining pressure, pore pressure, and applied axial load were independently varied.

Pore fluid flowed in the direction of maximum compression and was made available to the sample by means of a porous plug and piston. Highly porous spacers distributed the pore

Copyright ( 1975 by the American Geophysical Union. fluid evenly over the ends of the sample. The pore fluid used in these experiments was argon. Since argon is a gas, the low product of its compressibility times viscosity (compared with that of a liquid) reduced the amount of time necessary to measure permeability. Also since argon is chemically inert, it was only necessary to consider the mechanical effects of the pore fluid.

Permeability was measured by using a transient technique similar to that of Brace et al. [1968] and Sanyal et al. [1972]. Upon equilibration of the sample, valves $A$ and $B$ (Figure 1) were closed in order to isolate the sample from the pore pressure system. The pressure in the system was then raised by several bars. Upon thermal equilibration of the fluid in the system, valve B was opened, this event causing an instantaneous pore pressure gradient across the sample. The pore pressure gradient then decayed as fluid flowed through the sample and pressure built up on the low-pressure side (the high-pressure side had virtually infinite volume, and the pore pressure did not noticeably change during a measurement). The decay of the pore pressure gradient was measured with a highly sensitive differential pressure transducer that enabled us to measure accurately small pressure differences (the pressure difference was usually about 5 bars) at pore pressures of the order of 100 bars. Both the output of the differential transducer and the pore pressure at the high-pressure side of the sample were continuously recorded (Figure 2, top).

The pore pressure gradient decays exponentially with time (see appendix). Replotting the decay as log $\Delta p$ versus time yields a straight line with slope $m$ (Figure 2, bottom). Permeability is then determined from the slope by using the formula $k=m \mu \beta(L / A) V_{2}$, where $m$ is the slope of the line, $\mu$ and $\beta$ are the dynamic viscosity and compressibility of the pore fluid, $L$ and $A$ are the length and cross-sectional area of the sample, and $V_{2}$ is the system volume adjacent to the lowpressure side of the sample.

Owing to the low permeability of Westerly granite, experiments were performed at a maximum effective confining pressure of about 400 bars. This is because of the length of time required during which the most minute pore pressure leak could not be tolerated (experiments would typically last up to $10 \mathrm{~h}$ ).

\section{RESULTS}

Figures 3 and 4 present data for a sample that was previously loaded to high differential stress over 20 times. This procedure was used in an attempt to simulate more closely in 


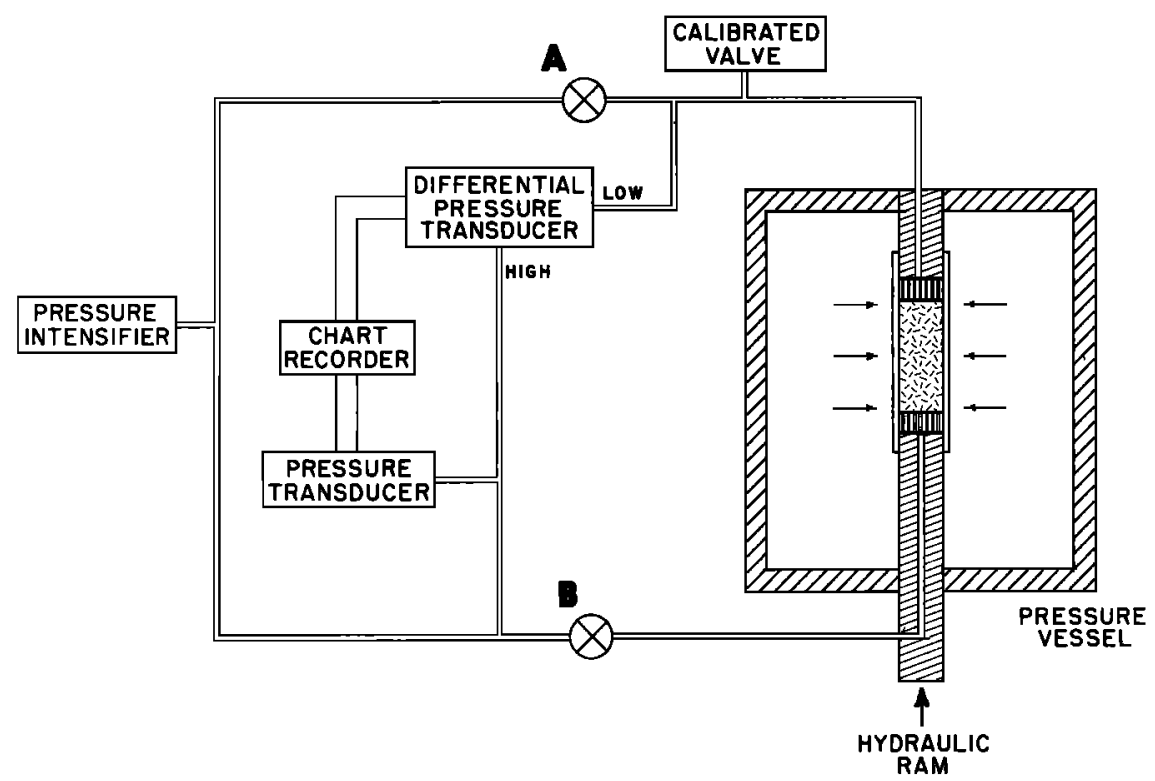

Fig. 1. Schematic illustration of the pore pressure system, sample assembly, and triaxial apparatus.

situ materials that may repeatedly undergo large stresses. The upper parts of these figures show volumetric strain (compression is positive) as a function of differential stress (the difference between the axial stress and the confining pressure). Permeability (measured in nanodarcys) is shown as a function of differential stress in the lower parts of the figures. These measurements were made at 500 bars of confining pressure and 110 bars of pore pressure (Figure 3 ) and at 250 bars of confin-

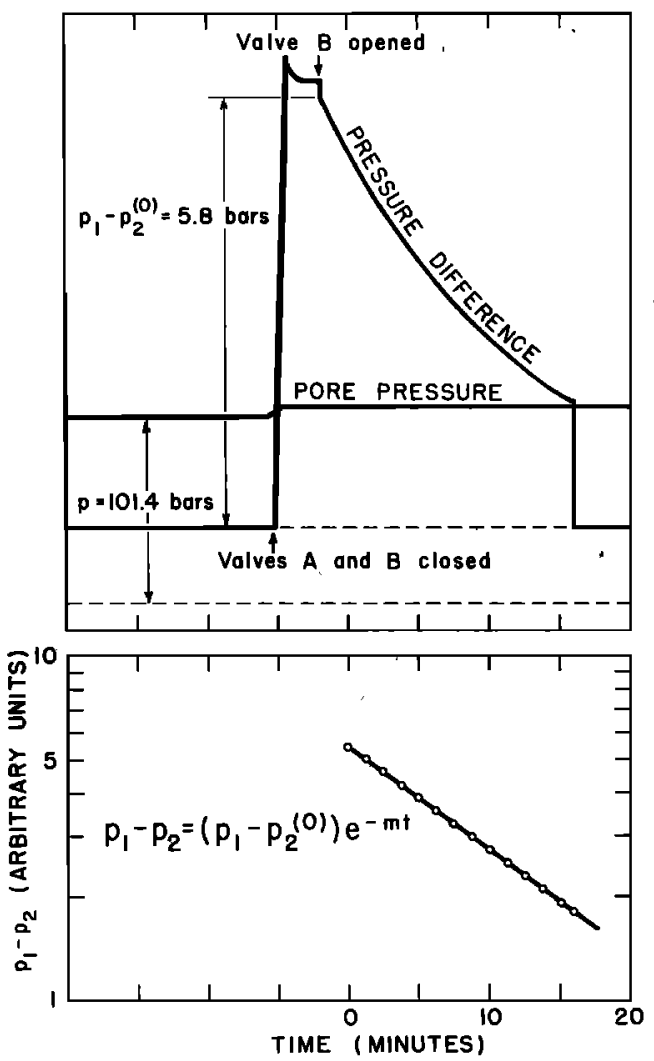

Fig. 2. (Top) Tracing of chart recorder data to illustrate experimental procedure.(Bottom) Replotting the decay of the pressure gradient to determine permeability from resultant straight line. Both the time origin and the units of pressure difference are arbitrary. ing pressure and 110 bars of pore pressure (Figure 4). As the sample was stressed at a strain rate of $10^{-5} \mathrm{~s}^{-1}$, the loading was periodically stopped, and permeability and volume strain were measured at the points shown.

The dashed line in the upper part of the figures represents the purely elastic compression of Westerly granite [from Brace et al., 1966]. Changes in crack volume are given by the difference between the actual volumetric strain and the expected elastic strain.

As a sample was initially stressed (Figures 3 and 4), the permeability slightly decreased. This phenomenon is presumably due to the closure of preexisting cracks, since the decrease in sample volume was greater than elastic. With further increase in differential stress the samples became dilatant, and the permeability correspondingly increased. As the differential stress was removed from the samples, the

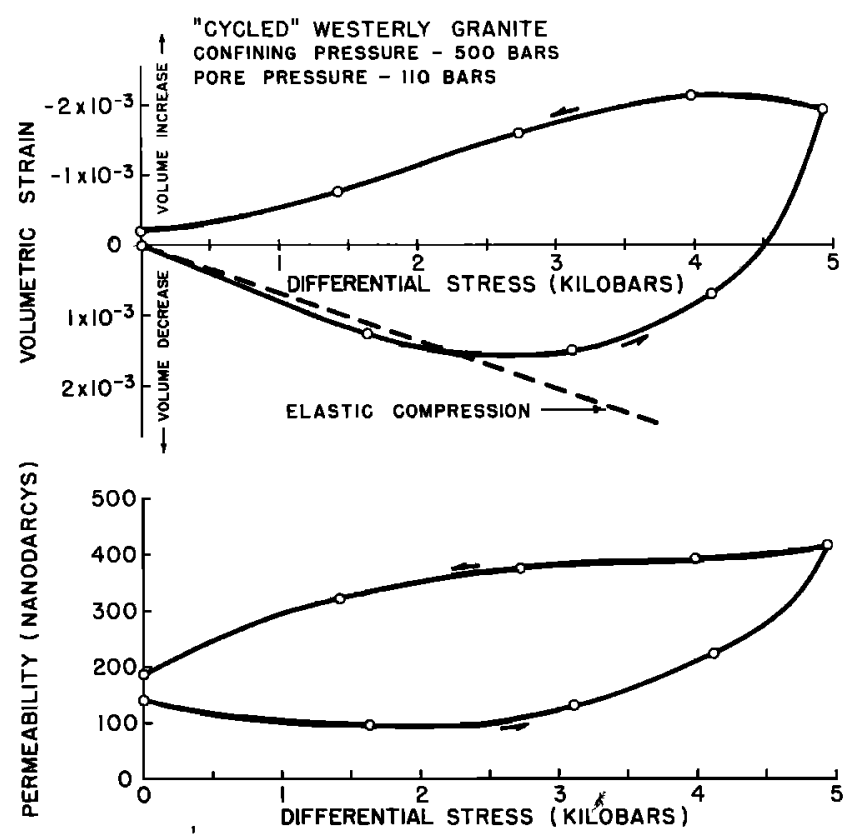

Fig. 3. Volumetric strain and permeability as a function of differential stress. 

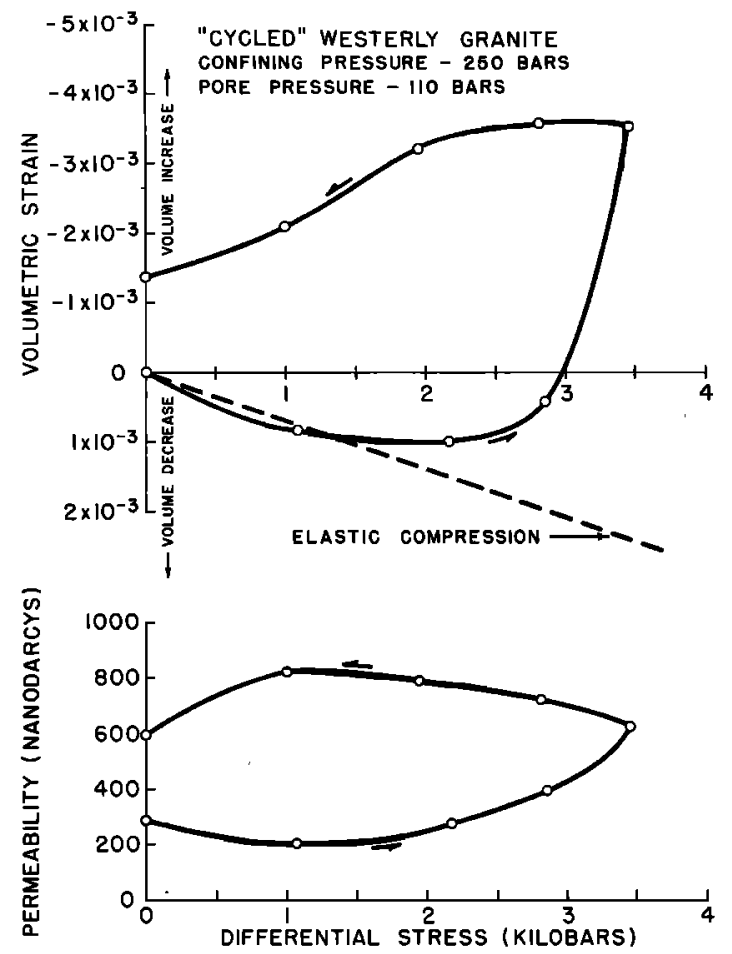

Fig. 4. Volumetric strain and permeability as a function of differential stress.

permeability remained quite high until almost all of the load had been removed.

Experiments on heat-treated samples were also performed in order to study the behavior of materials with greater initial porosity and permeability. These results are not reported, since the data presented in Figures 3 and 4 are fairly characteristic of the results for the heat-treated samples as well. Stressed to between 75 and $95 \%$ of their intact failure strength, all samples investigated showed an increase in permeability of between 200 and $400 \%$. With decreasing stress the permeability was characteristically quite high until most of the load was removed. In this regard, the small increase in permeability with decreasing differential stress apparent in Figure 4 is somewhat anomalous. In all the other samples investigated the permeability remained either constant or decreased slightly with most of the decrease of differential stress.

Unless a sample was quite close to the intact failure stress (as reported by Mogi [1966] for an initially intact sample under the same effective confining pressure), the volumetric strain did not appreciably change during the time that it took to measure permeability. In Figure 3, 4.94 kbar represents $73 \%$ of the intact failure strength; however, the repeated stress cycles and time spent under high differential stress have apparently weakened the sample. Judging by the time-dependent behavior of the strain, 4.94 kbar probably represents more like $90 \%$ of the failure stress. Similarly, in Figure 4, 3.43 kbar represents about $90-95 \%$ of the failure stress. For the data shown in Figure 3, only the volumetric strain at 4.94 kbar was noticeably dependent on time; it was $-0.85 \times 10^{-3}$ immediately after the stress was applied and $-2.14 \times 10^{-8}$ (as shown) when the permeability measurement was completed (about 30 min later). In Figure 4, only the volumetric strain at $3.43 \mathrm{kbar}$ was noticeably time dependent, going from $-0.4 \times 10^{-3}$ to $-3.52 \times 10^{-9}$ in about $30 \mathrm{~min}$.
During an experiment the output of the strain gauges was continuously recorded as a function of time. The gauges indicate that the time-dependent volumetric strain, or creep, that occurs at high stress is caused by growth of axially oriented cracks, since the time-dependent strain primarily involved the radial strain component. Scholz [1968] discusses room temperature creep in Westerly granite to some detail.

The permeability under hydrostatic stress shown in Figures 3 and 4 is about $50 \%$ higher than that reported by Brace et al. [1968] for intact samples of Westerly granite. This situation is evidently caused by the crack porosity introduced by the previous stress cycles. A hydrostatic compression test showed $0.25 \%$ crack porosity in the sample at the beginning of the experiment shown in Figure 3, whereas Brace et al. [1966] reported crack porosities of $0.16 \%$ in intact Westerly granite. Thus our results for previously cycled samples at hydrostatic pressure seem fairly consistent with those of Brace et al. [1968].

\section{Discussion and Conclusions}

Brace and Byerlee [1967] showed that dilatant microcracks are strongly oriented parallel to the axis of maximum compression. These cracks would seem therefore to affect greatly such properties as permeability and electrical conductivity measured in the directing maximum compression. Our work has shown, however, that although permeability is quite dependent upon dilatant volume changes, it seems that it is less dependent on dilatancy than is electrical conductivity. For dilatant volume changes similar to those reported here, Brace and Orange [1968] found an increase of more than an order of magnitude in conductivity, whereas we repeatedly found increases in permeability of about $300 \%$.

This result suggests that dilatant microcracks are somewhat isolated from each other. With increasing differential stress, cracks not oriented parallel to the axis of maximum compression tend to close. This process restricts flow between the opening dilatant cracks and thereby limits the increase in permeability. Since electrical conductivity is dependent on surface conduction as well as ionic conduction [Brace et al., 1965], flow can be restricted by extremely narrow cracks that nevertheless permit significant conductivity increases. Another observation supporting the suggestion that dilatant microcracks are fairly well isolated is that no permeability change (that is, no change in the slope $m$ ) was noticeable during the time-dependent crack growth that took place in samples while they were at high differential stress.

With much of the decrease of differential stress the permeability remains fairly constant because there is no significant crack closure as the stress is initially removed [Zaback and Byerlee, 1974] and because with further decreases of differential stress, two competing effects determine the permeability. Flow decreases through the axial cracks as they begin to close, but flow increases through the opening nonaxial cracks. This interpretation explains the increase in permeability with decreasing differential stress shown in Figure 4, the nonaxial cracks temporarily dominating the behavior of the sample.

Nur [1974], Scholz [1974], and Anderson and Whitcomb [1973] have suggested a diffusion coefficient (equal to $k / \mu \beta$ ) of $10^{4} \mathrm{~cm}^{2} / \mathrm{s}$ for fluid flow in the focal regions of the earthquakes that they considered. To compare our results with theirs, we must assume an appropriate $\mu$ and $\beta$. Assuming that 400 bars of effective stress is representative of an approximate depth of $2 \mathrm{~km}$, we can estimate a hydrostatic pore pressure of 
about 220 bars and a temperature of roughly $75^{\circ} \mathrm{C}$. Using these values and considering the data in Figure 3, we see that the maximum permeability (about 400 nanodarcys) corresponds to a diffusion coefficient of about $2 \times 10^{-2} \mathrm{~cm}^{2} / \mathrm{s}$, some 6 orders of magnitude less than that suggested by analysis of field data. This discrepancy is much too large to be compensated for by any reasonable assumption about the fluid phase. It appears therefore that if dilatancy-fluid diffusion occurs in situ and if diffusion coefficients of about $10^{4} \mathrm{~cm}^{2} / \mathrm{s}$ are indeed reasonable, fluid flow does not take place through microcracks. Rather, dilatancy and fluid flow must occur on the scale of joints and fractures.

\section{APPPENDIX}

From Darcy's law, flow through the sample is governed by the equation

$$
q=\frac{k A}{\mu} \frac{\left(p_{1}-p_{2}\right)}{L}
$$

where $q$ is the volumetric flow rate, $k$ is the permeability, $\mu$ is the dynamic viscosity, $A$ and $L$ are the cross-sectional area and length of the sample, and $\left(p_{1}-p_{2}\right)$ is the difference in pore pressure across the sample. The subscripts 1 and 2 refer to the high-pressure and low-pressure ends of the sample, respectively.

In using Darcy's law we assume that there is a linear pressure gradient across the sample and that the flow rate is only a function of time. Since the mass flow rate $Q(Q=q \rho$, where $\rho$ is the fluid density) into the sample must be the same as that out of the sample, then, for $q_{1} \simeq q_{2}$, as was assumed, $\rho_{1} \simeq \rho_{2}$. This situation requires a small pore pressure gradient across the sample (especially when gas is the pore fluid).

Since $p_{1}$ remains constant throughout experiments, $V_{1}$ is virtually infinite. The fluid density on the low-pressure side of the sample is, at any given time,

$$
\rho_{2}=\rho_{2}{ }^{(0)}+\int_{0}^{t} \frac{Q}{V_{2}} d t
$$

where the superscript $(0)$ refers to initial conditions.

From the definition of the isothermal compressibility of the fluid, $\beta$,

$$
p_{2}={p_{2}}^{(0)}+\frac{1}{\beta \rho_{2}{ }^{(0)}}\left(\rho_{2}-{\rho_{2}}^{(0)}\right)
$$

Therefore for small pressure gradients,

$$
p_{2}=p_{2}{ }^{(0)}+\frac{1}{\beta V_{2}} \int_{0}^{t} q d t
$$

Substituting Darcy's law yields

$$
p_{1}-p_{2}{ }^{(0)}=\frac{L \mu q}{A k}+\frac{1}{\beta V_{2}} \int_{0}^{t} q d t
$$

and differentiating with respect to time yields

$$
\frac{d q}{d t}-\frac{k A}{\beta V_{2} L_{\mu}} q=0
$$

The solution of this equation is

$$
q=q^{(0)} e^{-m t}
$$

where $m=k A / \beta V_{2} \mu L$. Thus resubstituting Darcy's law yields

$$
p_{1}-p_{2}=\left(p_{1}-p_{2}{ }^{(0)}\right) e^{-m t}
$$

Except for our slightly different boundary conditions this solution is similar to that given by Sanyal et al. [1972] and Brace et al. [1968]. As is discussed by Brace, the excellent correspondence between the theoretical and observed decay characteristics provides confirmation of Darcian flow.

\section{REFERENCES}

Anderson, D. L., and J. H. Whitcomb, The dilatancy-diffusion model of earthquake prediction, in Proceedings of Conference on Tectonic Problems of the San Andreas Fault Zone, edited by R. C. Kovatch and A. Nur, pp. 417-426, Stanford University Press, Palo Alto, Calif., 1973.

Brace, W. F., A. S. Orange, and T. R. Madden, The effect of pressure on the electrical resistivity of water-saturated crystalline rocks, $J$. Geophys. Res., 70(22), 5669-5678, 1965.

Brace, W. F., B. W. Paulding, Jr., and C. H. Scholz, Dilatancy in the fracture of crystalline rocks, J. Geophys. Res., 71(16), 3939-3953, 1966.

Brace, W. F., and J. D. Byerlee, Recent experimental studies of brittle fracture of rocks, in Failure and Breakage of Rock, Proceedings of 8th Symposium on Rock Mechanics, edited by C. Fairhurst, Port City Press, Baltimore, Md., 1967.

Brace, W. F., and A. S. Orange, Electrical resistivity changes in saturated rocks during fracture and frictional sliding, J. Geophys. Res., 73(4), 1433-1445, 1968.

Brace, W. F., J. B. Walsh, and W. T. Frangos, Permeability of granite under high pressure, J. Geophys. Res., 73(6), 2225-2236, 1968.

Mogi, K., Some precise measurements of fracture strength of rocks under uniform compressive stress, Felsmechanik Ingenieurgeol., 4(1), 41-55, 1966.

Nersesov, I. L., A. N. Semonova, and I. G. Simbireva, Physical Basis of Foreshocks, Nauka, Moscow, 1969.

Nur, A., Dilatancy, pore fluids, and premonitory variations of $t_{\mathrm{g}} / t_{p}$ travel times, Bull. Seismol. Soc. Amer., 62(5), 1217-1222, 1972.

Nur, A., Matsushiro, Japan, earthquake swarm: Confirmation of the dilatancy-fluid diffusion model, Geology, 2, 217, 1974.

Sanyal, S. K., R. M. Pirnie III, G. O. Chen, S. S. Marsden, Jr., A novel liquid permeameter for measuring very low permeability, Soc. Petrol. Eng. J., 206-210, June 1972.

Scholz, C. H., Mechanism of creep in brittle rock, J. Geophys. Res., 73(10), 3295-3302, 1968.

Scholz, C. H., Postearthquake dilatancy recovery, Geology 2(11), $551,1974$.

Schol, C. H., L. R. Sykes, and Y. P. Aggarawal, Earthquakes prediction: A physical basis, Science, 181, 803-810, 1973.

Semenov, A. N., Variations in the travel time of transverse and longitudinal waves before violent earthquakes, Izv. Acad. Sci. USSR Phys. Solid Earth, 3, 245-248, 1969.

Zoback, M. D., and J. D. Byerlee, The effect of cyclic differential stress on dilatancy in Westerly granite under uniaxial and triaxial conditions, submitted to J. Geophys. Res., 1974.

(Received June 27, 1974; revised September 25, 1974; accepted October 3, 1974.) 